\title{
The Influence of Corticosteroids on Diagnostic Accuracy of Biopsy for Primary Central Nervous System Lymphoma
}

\author{
Mashary Binnahil, Karolyn Au, Jian-Qiang Lu, Blaise Matthew Wheatley, Tejas Sankar
}

\begin{abstract}
Classical neurosurgical teaching suggests that corticosteroid administration reduces the diagnostic yield of stereotactic brain biopsy for primary central nervous system lymphoma (PCNSL). In a single-center series spanning 6 years, we reviewed 155 consecutive biopsy patients, 135 treated with prebiopsy corticosteroids. PCNSL was correctly diagnosed on initial biopsy in 15 of 16 steroid-treated patients; in the single nondiagnostic specimen, polymerase chain reaction reanalysis by an outside institution showed evidence of lymphoproliferative disease consistent with PCNSL. Our data challenge the notion that it is necessary to withhold corticosteroid therapy for cerebral edema in patients awaiting stereotactic biopsy for suspected PCNSL.
\end{abstract}

RÉSUMÉ: Influence des corticostéroïdes sur l'exactitude du diagnostic lors d'une biopsie pour lymphome primitif du système nerveux central. Selon l'enseignement neurochirurgical classique, l'administration de corticostéroÏdes diminue le rendement diagnostique de la biopsie stéréotaxique du cerveau effectuée pour un lymphome primitif du système nerveux central (LPSNC). Nous avons revu les biopsies effectuées chez 155 patients traités dans un même centre sur une période de 6 ans, dont 135 avaient reçu des corticostéroïdes avant la biopsie. Un LPSNC a été diagnostiqué correctement lors de la biopsie initiale chez 15 sur 16 des patients traités par des stéroïdes. Dans le seul spécimen sans diagnostic, une réanalyse au moyen de la réaction en chaîne par polymérase effectuée dans une autre institution a montré la présence d'une maladie lymphoproliférative compatible avec un LPSNC. Nos données remettent en question la notion qu'il est nécessaire d'éviter le traitement de l'œdème cérébral par des corticostéroïdes chez les patients en attente d'une biopsie stéréotaxique chez qui on soupçonne la présence d'un LPSNC.

Keywords: Lymphoma, Neuro-Oncology, Neuropathology, Neurosurgery

doi:10.1017/cjn.2016.255

Can J Neurol Sci. 2016; 43: 721-725

\section{INTRODUCTION}

Primary central nervous system lymphoma (PCNSL) is a form of extranodal, high-grade, non-Hodgkin B-cell neoplasm. ${ }^{1}$ Controversy surrounds the pathogenesis and the management of PCNSL. A key management dilemma pertains to the administration of corticosteroids before confirmed tissue diagnosis of PCNSL. Although steroids have a therapeutic role in brain tumors based on their ability to restore the blood-brain barrier and reduce vasogenic edema, it is now known that steroids have a cytolytic effect on lymphoma cells. ${ }^{2,3}$ This effect appears to be mediated by cytoplasmic receptors that, when bound to glucocorticoid, translocate to the nucleus and induce apoptosis. ${ }^{3}$ The effect is variable, with some cases showing scattered apoptotic bodies among tumor cells and others showing numerous apoptotic bodies with few remaining intact tumor cells. ${ }^{3,4}$ Additionally, the effect may be accompanied by at least partial radiological regression in up to $40 \%$ of cases. ${ }^{4}$ These issues raise the concern that steroid use in patients with PCNSL may result in a nondiagnostic biopsy. Consequently, a common clinical practice is, where possible, to avoid administering steroids for suspected PCNSL until after brain biopsy. ${ }^{3,5}$ A recent study has challenged this long-held practice. ${ }^{6}$ In it, the authors conducted a retrospective analysis to determine the effect of using steroids preoperatively on the accuracy of brain biopsy for PCNSL. Interestingly, only eight patients of $68(12 \%)$ who had been given steroids needed a repeat brain biopsy to confirm
PCNSL. In addition, this rate of nondiagnostic biopsy was not significantly different from that observed in patients who had not received any preoperative steroids (5 of 39 patients, $13 \%)^{6}$

The purpose of this study is to present our institutional experience with the use of steroids for patients with suspected PCNSL. Specifically, we were interested in whether the rate of nondiagnostic stereotactic brain biopsy is increased in patients with suspected PCNSL who receive corticosteroids before any biopsy procedure.

\section{METHODS}

After ethical approval was obtained from our institutional Research Ethics Board, we accessed the prospectively maintained operative database at the University of Alberta Hospital-the primary neurosurgical hospital for the city of Edmonton-to identify all patients who had undergone stereotactic biopsy for a new brain lesion between March 2007 and March 2013. In total,

From the Division of Neurosurgery, Department of Surgery (MB, BLMW, TS); Division of Neuropathology, Department of Pathology (JQL), University of Alberta, Alberta, Canada; Division of Neurosurgery, Department of Surgery (KA), University of Toronto, Toronto, Canada.

Received October 28, 2015. Final Revisions Submitted January 18, 2016. Date of ACCEPTANCE FEBRUARY 2, 2016.

Correspondence to: Tejas Sankar, 2D Department of Surgery, WCM Health Sciences Centre, 8440-112 Street NW, Edmonton, AB, Canada T6G 2B7. Email: tsankar@ualberta.ca 


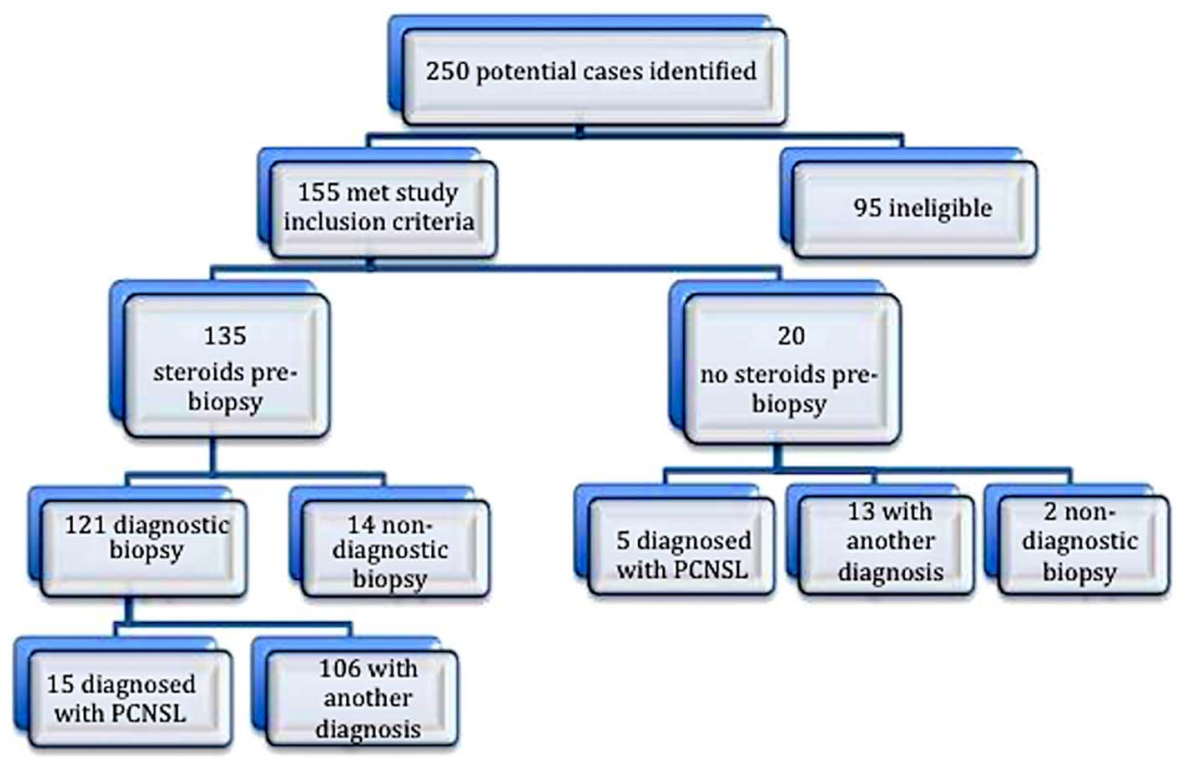

Figure 1: Summary of diagnostic biopsy yield across all study patients.

250 potential cases were initially identified (Figure 1). Subsequently, we searched the electronic clinical and radiological records of all 250 potential patients using the provincial Electronic Health Record and Alberta Health Services Picture Archiving and Communication System, respectively. Open biopsy cases were excluded $(n=36)$ because it would be exceedingly rare for the large volume of pathological tissue obtained during such cases to result in a nondiagnostic biopsy. A detailed chart review was done for all remaining eligible patients to identify their clinical presentation, dose and duration of corticosteroid exposure, and operative and pathology reports. Cases with missing pathology, operative, or perioperative corticosteroid exposure information were also excluded $(n=31)$. An additional 28 cases were excluded for the following reasons: seven duplicated database records, six falling outside the specified date range, seven purely abscess drainage, four purely cyst aspiration, three with a previous biopsy outside the specified date range, and one with documented technical errors during biopsy. Finally, we searched the regional lymphoma registry to cross-reference our data and identify any cases of PCNSL during the study period that may have been missed by our original search strategy.

\section{Results}

A total of 155 patients met eligibility criteria (Figure 1) and were reviewed in detail. Our search of the regional lymphoma registry did not identify any PCNSL patients who were not captured in this initial list of 155 . A total of 135 of 155 patients $(87.1 \%)$ received corticosteroids before biopsy and $20(12.9 \%)$ did not. Of the 135 who received corticosteroids, 121 had a diagnostic biopsy $(89.6 \%)$ and 14 had a nondiagnostic biopsy $(10.4 \%)$. Of the 121 diagnostic biopsies, 15 (12.4\%) were PCNSL. Figure 2 shows typical pathological features in two cases receiving corticosteroids for 3 and 7 days respectively, both ultimately diagnosed with PCNSL.

Ten of the 14 patients who had a nondiagnostic biopsy, and who had received preoperative steroids, went on to have a second biopsy that confirmed a diagnosis other than PCNSL. Three additional patients were ultimately diagnosed with conditions other than PCNSL on the basis of clinical or radiological features or on followup extracranial biopsy (Table 1). Specifically, patient 7 had two consecutive nondiagnostic brain biopsies, but ultimately had a biopsy from the submandibular gland that was reported as metastatic lung carcinoma. Patient 11 did not undergo a second biopsy because she had stable brain lesions that remained unchanged for 5 years on follow-up imaging; this would not be in keeping with the natural history of PCNSL. Patient 12 had two negative brain biopsies but the radiological picture was consistent with a diagnosis of benign midbrain cyst and certainly atypical for PCNSL.

The pathological specimen from the last outstanding patient (14) with an initially nondiagnostic biopsy after steroid treatment was reviewed at another center for a second opinion. Polymerase chain reaction (PCR) analysis performed at the second institution was highly suggestive of low-grade B-cell lymphoproliferative disease. However, it was felt that another biopsy was needed to confirm the diagnosis; indeed, a second biopsy was done that confirmed low-grade B-cell lymphoma, and this patient went on to receive treatment for PCNSL. It is worth noting that the diagnosis of PCNSL is now restricted to primary diffuse large B-cell-as opposed to low grade-lymphoma confined to the central nervous system (and/or to the eye) that occurs in immunocompetent patients. ${ }^{7}$ Furthermore, the clinical and radiological progression of this patient was atypical for PCNSL because there was no symptomatic progression of the disease and there was no tumor seen on rain magnetic resonance imaging (MRI) 7 years after the initial biopsy. Accordingly, it is reasonable to consider that this particular case may originally have been misclassified as PCNSL.

Of the 20 patients who did not receive prebiopsy corticosteroids, five $(25 \%)$ were diagnosed with PCNSL, 13 (65\%) had another diagnosis, and two $(10 \%)$ had a nondiagnostic biopsy. These last two patients each underwent a repeat biopsy procedure; one biopsy showed the sclerotic wall of a chronically inflamed abscess cavity, and the other demonstrated high-grade glioma (Table 2). 

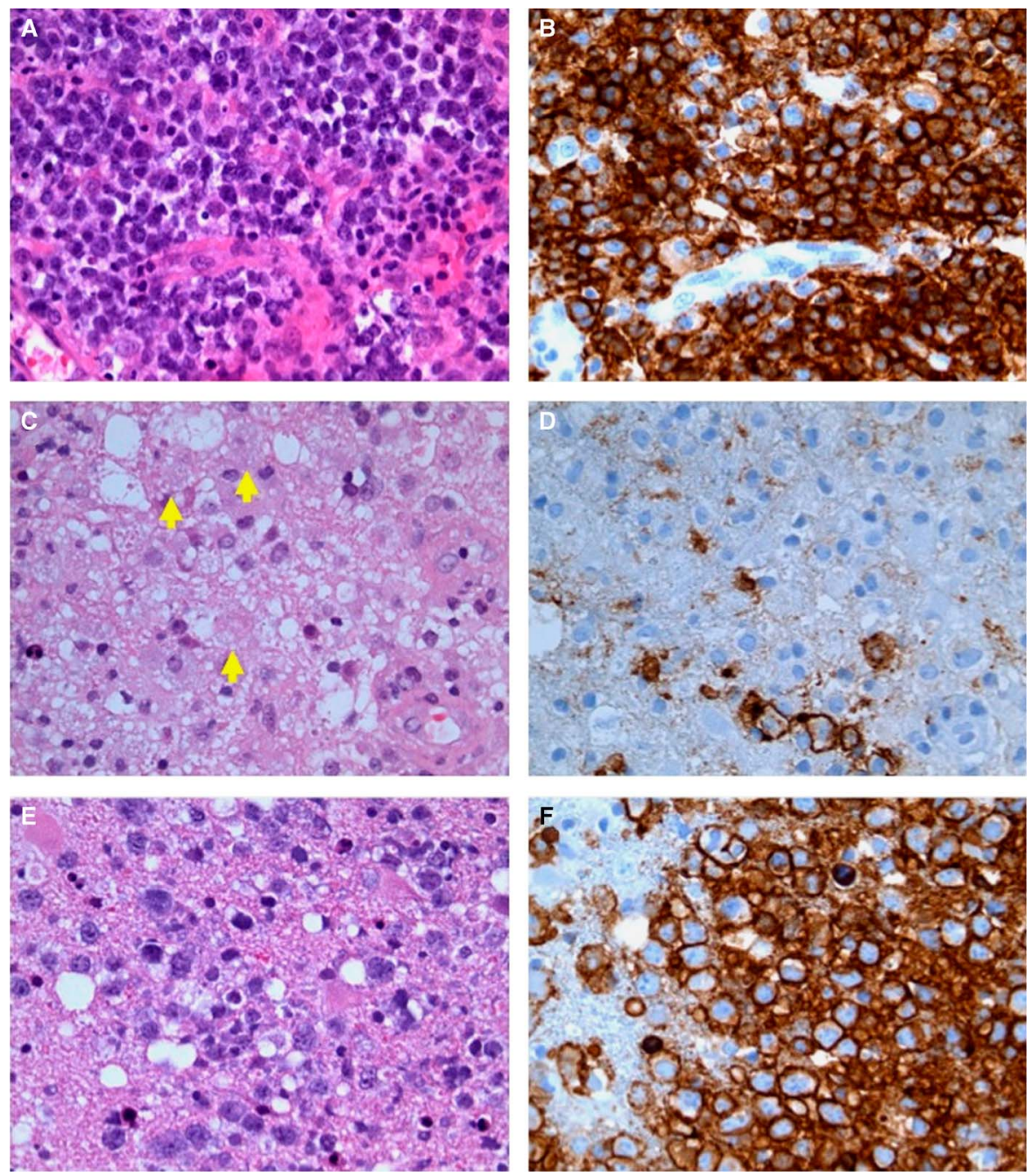

Figure 2: Photomicrographs of illustrative PCNSL cases. Biopsy of a right frontal lesion in a 71 year-old female treated with steroids pre-operatively for 3 days shows (A) aggregates of atypical large lymphoid cells with scattered small dark apoptotic bodies, and $(B)$ extensive immunoreactivity for the B-cell marker CD20. In comparison, a biopsy of a left frontal lesion in a 50 year-old male treated with steroids pre-operatively for 7 days exhibits some areas with $(C)$ markedly reactive changes including frequent macrophages containing prominent granular cytoplasm and scattered small dark apoptotic bodies but (D) occasional CD20-immunoreactive B-cells. In other areas, we see (E) frequent atypical large lymphoid cells along with scattered small dark apoptotic bodies, and $(F)$ their immunoreactivity for CD20. Original magnification $400 x(A-F)$.

In total, we identified 20 patients diagnosed with PCNSL, of whom 15 had received corticosteroids prebiopsy and five had not. Twelve PCNSL patients were men (60\%). The median age for men and women was 63 and 67 years, respectively. The overall rate of initial nondiagnosis in the steroid-treated and steroid-naïve groups was not significantly different (14/135 vs. $2 / 20$, Fisher's exact test $\mathrm{p}=0.99$ ). Furthermore, the rate of PCNSL nondiagnosis at initial biopsy was not significantly different between steroid-treated and steroid-naïve cases ( $1 / 14$ vs. 0/2, Fisher's exact test $p=0.99$ ).

Dexamethasone was the only form of corticosteroid used in all steroid-treated patients, with a mean dose of $4 \mathrm{mg}$ every 6 hours, which is the standard dosing regimen in our institution for patients with vasogenic edema. Among treated patients, the median duration of dexamethasone treatment before biopsy was 4 days (range, 2-45 days).

\section{Discussion}

The effect of corticosteroids on diagnostic yield of biopsy in patients with PCNSL remains a source of debate. Traditional neurosurgical teaching has emphasized that it is important to avoid steroids before biopsy when PCNSL is suspected because corticosteroids may be cytotoxic to lymphoma cells, leading to false-negative biopsy results. ${ }^{2,3}$ Our findings add to the growing body of evidence that challenges this long-held practice. Simply put, corticosteroid treatment did not prevent the diagnosis of PCNSL in our series, irrespective of the duration of steroid therapy before biopsy. Notably, we did not find any cases of so-called "ghost tumor," which has previously been reported in the setting of intracranial lymphoma. ${ }^{8}$ Our population of PCNSL patients is a fairly representative population, well within the expected age and sex distributions for the disease. 


\section{Table 1: Patients with a negative initial biopsy who received prebiopsy corticosteroids}

\begin{tabular}{|c|c|c|c|c|}
\hline Patient & Age and sex & First biopsy result & Corticosteroid dose & Second biopsy result \\
\hline 1 & $22 \mathrm{M}$ & Edematous gray matter with focal vascular proliferation & $\begin{array}{l}\text { Dexamethasone } 4 \mathrm{mg} \mathrm{PO} / \mathrm{IV} \text { for } \\
3 \text { days }\end{array}$ & Pilocytic astrocytoma (WHO I) \\
\hline 2 & $49 \mathrm{M}$ & $\begin{array}{l}\text { Thrombosed blood vessels, necrotic tissue, and reactive } \\
\text { brain }\end{array}$ & $\begin{array}{l}\text { Dexamethasone } 4 \mathrm{mg} \mathrm{PO} / \mathrm{IV} \text { for } \\
5 \text { days }\end{array}$ & $\begin{array}{l}\text { Second stereotactic biopsy nondiagnostic } \\
\text { Third open biopsy showed GBM (WHO IV) }\end{array}$ \\
\hline 3 & $56 \mathrm{~F}$ & Fragments of white matter with autolysis & $\begin{array}{l}\text { Dexamethasone } 4 \mathrm{mg} \text { PO/IV for } \\
2 \text { days }\end{array}$ & Anaplastic glioma (WHO III) \\
\hline 4 & $26 \mathrm{M}$ & Nonspecific inflammatory and reactive changes & $\begin{array}{l}\text { Dexamethasone } 4 \mathrm{mg} \text { PO/IV for } \\
4 \text { days }\end{array}$ & Germinoma \\
\hline 5 & $70 \mathrm{M}$ & $\begin{array}{l}\text { White and gray matter with focal atypical glial } \\
\text { hypercellularity }\end{array}$ & $\begin{array}{l}\text { Dexamethasone } 4 \mathrm{mg} \text { PO/IV for } \\
3 \text { days }\end{array}$ & Ganglioglioma \\
\hline 6 & $47 \mathrm{M}$ & $\begin{array}{l}\text { Fragments of white matter with possible infiltrating } \\
\text { glioma margin }\end{array}$ & $\begin{array}{l}\text { Dexamethasone } 4 \mathrm{mg} \text { PO/IV for } \\
4 \text { days }\end{array}$ & GBM (WHO IV) \\
\hline 7 & $56 \mathrm{M}$ & Nonspecific ischemic changes & $\begin{array}{l}\text { Dexamethasone } 4 \mathrm{mg} \text { PO/IV for } \\
6 \text { days }\end{array}$ & $\begin{array}{l}\text { Nonspecific changes. Submandibular gland biopsy } \\
\text { ultimately showed metastatic carcinoma }\end{array}$ \\
\hline 8 & $26 \mathrm{~F}$ & Chronic inflammatory changes & $\begin{array}{l}\text { Dexamethasone } 4 \mathrm{mg} \text { PO/IV for } \\
3 \text { days }\end{array}$ & $\begin{array}{l}\text { Autopsy showed inflammatory demyelinating } \\
\text { disease }\end{array}$ \\
\hline 9 & $29 \mathrm{~F}$ & Minor nonspecific changes & $\begin{array}{l}\text { Dexamethasone } 4 \mathrm{mg} \text { PO/IV for } \\
7 \text { days }\end{array}$ & Inflammatory demyelinating process \\
\hline 10 & $53 \mathrm{~F}$ & $\begin{array}{l}\text { Fragment of neurological tissue with a margin of } \\
\text { necrosis }\end{array}$ & $\begin{array}{l}\text { Dexamethasone } 4 \mathrm{mg} \text { PO/IV for } \\
5 \text { days }\end{array}$ & GBM (WHO IV) \\
\hline 11 & $49 \mathrm{~F}$ & Nonspecific inflammatory changes & $\begin{array}{l}\text { Dexamethasone } 4 \mathrm{mg} \text { PO/IV for } \\
3 \text { days }\end{array}$ & No second biopsy done \\
\hline 12 & $61 \mathrm{M}$ & Cerebral tissues with no pathological diagnosis & $\begin{array}{l}\text { Dexamethasone } 4 \mathrm{mg} \text { PO/IV for } \\
6 \text { days }\end{array}$ & Fragments of neuropil \\
\hline 13 & $73 \mathrm{M}$ & Fragments of blood with possible glial fragments & $\begin{array}{l}\text { Dexamethasone } 4 \mathrm{mg} \text { PO/IV for } \\
2 \text { days }\end{array}$ & GBM (WHO IV) \\
\hline 14 & $63 \mathrm{~F}$ & $\begin{array}{l}\text { No diagnostic biopsy in our center } \\
\quad \text { (please see text for details) }\end{array}$ & $\begin{array}{l}\text { Dexamethasone } 4 \mathrm{mg} \text { PO/IV for } \\
3 \text { days }\end{array}$ & Low-grade B-cell lymphoproliferative disorder \\
\hline
\end{tabular}

Highlighted sections indicate cases discussed in greater detail in the text.

$\mathrm{F}=$ female GBM = glioblastoma multiforme; IV = intravenous; $\mathrm{M}=$ male; $\mathrm{PO}=$ by mouth; $\mathrm{WHO}=$ World Health Organization Classification of Brain Tumors 2007

We found a single outlying patient (14) who received corticosteroids and had an initial nondiagnostic biopsy, but who was then assigned a diagnosis of low-grade B-cell lymphoma following a second opinion from another center, aided by PCR analysis. PCR is now established as an effective way to diagnose PCNSL, although its use for diagnosis of PCNSL is not yet widespread. ${ }^{9}$ That being said — and as we mentioned previously — in retrospect, it may have been inaccurate to label this particular case as PCNSL, given that it did not exhibit the typical pathological and clinical features of the disease.

There are several potential reasons why we observed near-perfect diagnostic yield for PCNSL with stereotactic biopsy, despite prebiopsy steroid use. For one, our biopsies were all performed in the MRI era, with high-resolution, thin-cut MRI scans obtained in all patients relatively close to the biopsy date (the average interval between MRI scanning and biopsy was 4 days). Furthermore, all biopsies in our series were performed by experienced stereotactic neurosurgeons with access to a high-quality frameless stereotactic neuronavigation system. Taken together, these factors almost certainly reduce the likelihood of a nondiagnostic biopsy resulting from targeting error or other technical errors during surgery.

This study is limited by its retrospective and nonrandomized nature. The number of PCNSL patients identified in our series was small, though this might be explained at least partially by the rarity of the condition. That we found a higher proportion of patients diagnosed with PCNSL in the nonsteroid group than in the steroid group $(5 / 20=25 \%$ vs. $15 / 135=11 \%)$ may reflect a preexisting bias toward withholding prebiopsy steroids in suspected PCNSL cases, which might have influenced our ultimate conclusions.

Table 2: Patients with a negative first biopsy who did not receive prebiopsy corticosteroids

\begin{tabular}{|c|c|c|c|}
\hline Patients & Age and sex & First biopsy result & Second biopsy result \\
\hline 1 & $44 \mathrm{M}$ & Necrotic tissue, insufficient for diagnosis & Sclerotic wall of chronically inflamed abscess cavity \\
\hline 2 & $74 \mathrm{~F}$ & No pathological diagnosis & Infiltrating margin of high-grade glioma \\
\hline
\end{tabular}

$\mathrm{F}=$ female; $\mathrm{M}=$ male. 
Such a bias is not unexpected given traditional neurosurgical teaching regarding PCNSL, and is impossible to eliminate in a retrospective study. Finally, we might have missed some patients who received corticosteroids, had a lesion that regressed sufficiently on imaging so as to defer or preclude biopsy, and then died in future of PCNSL without ever having undergone a biopsy procedure. That being said, we did search our regional lymphoma registry and could not find any unaccounted cases of autopsyproven PCNSL.

\section{CONCLUSION}

Though retrospective, our series adds to a growing literature suggesting that corticosteroids do not substantially increase the likelihood of nondiagnostic biopsy in PCNSL. Provided that stereotactic biopsies are performed in a technically sound manner guided by current high-resolution MRI scans, our findings constitute further evidence arguing against the routine practice of withholding corticosteroid therapy for symptomatic cerebral edema in patients awaiting biopsy for suspected PCNSL.

\section{Disclosures}

The authors do not have anything to disclose.

\section{REFERENCES}

1. Miller DC, Hochberg FH, Harris NL, Gruber ML, Louis DN, Cohen H. Pathology with clinical correlations of primary central nervous system non-Hodgkin's lymphoma. The Massachusetts General Hospital experience 1958-1989. Cancer. 1994;74:1383-97.

2. Gametchu B. Glucocorticosteroid receptor-like antigen in lymphoma cell membranes: correlation to cell lysis. Science. 1987;236: 456-61.

3. Weller M. Glucocorticoid treatment of primary CNS lymphoma. J Neurooncol. 1999;43:237-9.

4. Mokhtari K, Houillier C, Hoang-Xuan K. Brain biopsy in a patient suffering from primary CNS lymphoma treated with steroids. Eur Assoc Neurooncol Mag. 2012;2:95-6.

5. Gunduz K, Pulido JS, McCannel CA, O’Neill BP. Ocular manifestations and treatment of primary central nervous system lymphomas. Neurosurg Focus. 2006;21:E9.

6. Porter AB, Giannini C, Kaufmann T, et al. Primary CNS lymphoma can be histologically diagnosed after previous corticosteroid use: a pilot study to determine whether corticosteroids prevent the diagnosis of primary CNS lymphoma. Ann Neurol. 2008;63: 662-7.

7. Giannini C, Dogan A, Salomao DR. CNS lymphoma: a practical diagnostic approach. Neuropath Exp Neurol. 2014;73:478-94.

8. Vaquero J, Martínez R, Rossi E, López R. Primary cerebral lymphoma: the "ghost tumor". Case report. J Neurosurg. 1984;60:174-6.

9. Shaw A, Iyer V, Rooney N, et al. Diagnosis of primary cerebral lymphomas: possible value of PCR testing in equivocal cases requiring rebiopsy. Br J Neurosurg. 2014;28:214-9. 